\title{
Endoscopic Retrograde Cholangiopancreatography
}

National Cancer Institute

\section{Source}

National Cancer Institute. Endoscopic Retrograde Cholangiopancreatography. NCI

Thesaurus. Code C16430.

A procedure in which the bile ducts, pancreatic duct, and gallbladder are examined using a combination of endoscopy and fluoroscopy. 